\title{
ORIGEN DEL PALACIO DE PEDRO I EN EL ALCÁZAR DE SEVILLA: EL MIRADOR HOY LLAMADO DE LOS REYES CATÓLICOS
}

\author{
Sebastián Fernández Aguilera \\ Ldo. en Geografía e Historia
}

\begin{abstract}
El presente trabajo, se inicia con la búsqueda del emplazamiento que pudo tener la gran puerta de la Antigua Capilla, de la que, tras su restauración y estudio, sabemos que existía con anterioridad a la obra mudéjar del palacio de Pedro I en Sevilla en 1365.

En esa búsqueda, y apoyándonos en los distintos estudios que se vienen realizando con motivo de restauraciones recientes, hemos llegado a la conclusión de que no se trata de carpintería reutilizada, sino que es toda la construcción de esa parte del palacio, adosada al anterior palacio gótico, y con distintas estancias desde el sótano hasta el Mirador, la que ya existía con anterioridad al rey Don Pedro, y con toda probabilidad obra de su padre el rey Alfonso XI, como se concluye en este artículo.
\end{abstract}

Palabras clave: Mudéjar; Mirador; Pedro I; Reyes Católicos; Alfonso XI; Sevilla; Palacio.

\section{THE ORIGIN OF PEDRO I'S PALACE IN THE ALCÁZAR OF SEVILLE: THE SO-CALLED BALCONY OF THE CATHOLIC KINGS}

This study originated with the search for the possible initial site of the main door of the Old Chapel, which, following its restoration and study, turned out to be older than the rest of the Mudéjar palace of King Pedro I (Seville, 1365).

During this investigation, and based on recent studies carried out as the result of several previous restorations, the author realized that this door was not relocated from another place. It had formed part of the earlier Gothic palace to which the construction of Pedro I's palace was attached at this juncture, with several rooms from basement to upper balcony predating the Mudéjar building, thereby concluding that it must have been the work of his father, King Alfonso XI.

Key words: Mudéjar; balcony; Pedro I; Catholic Kings; Alfonso XI; Seville; Palace.

La reciente restauración de las carpinterías de vanos -puertas y ventanas- del Palacio Mudéjar en el Alcázar de Sevilla ha ido acompañada de un trabajo de investigación sobre este tipo de carpinterías $^{1}$, en el que se han puesto de manifiesto una serie de diferencias entre las tres puertas mayores de las que conforman el conjunto, con las que se evidencia que cada una de ellas pertenece

\footnotetext{
${ }^{1}$ Fernández Aguilera, 2012.
} 


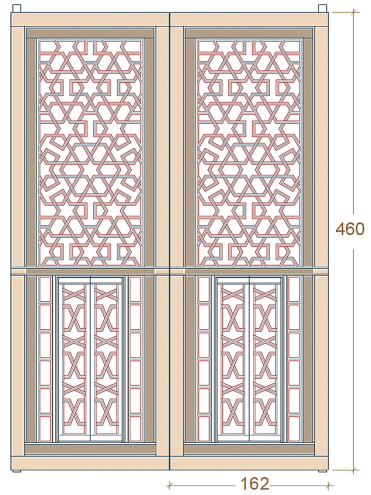

Puerta de la Alcoba Real

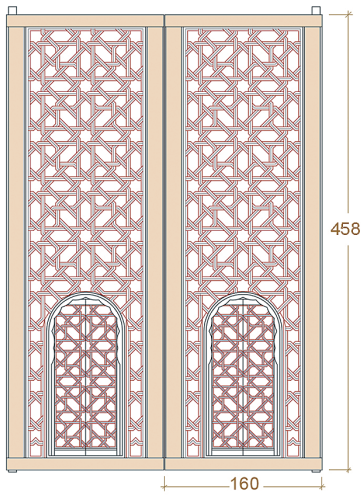

Puerta de la Antigua Capilla

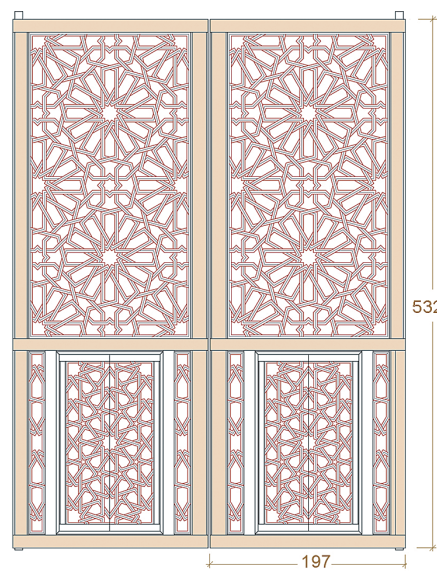

Puerta del Salón de la Media Naranja

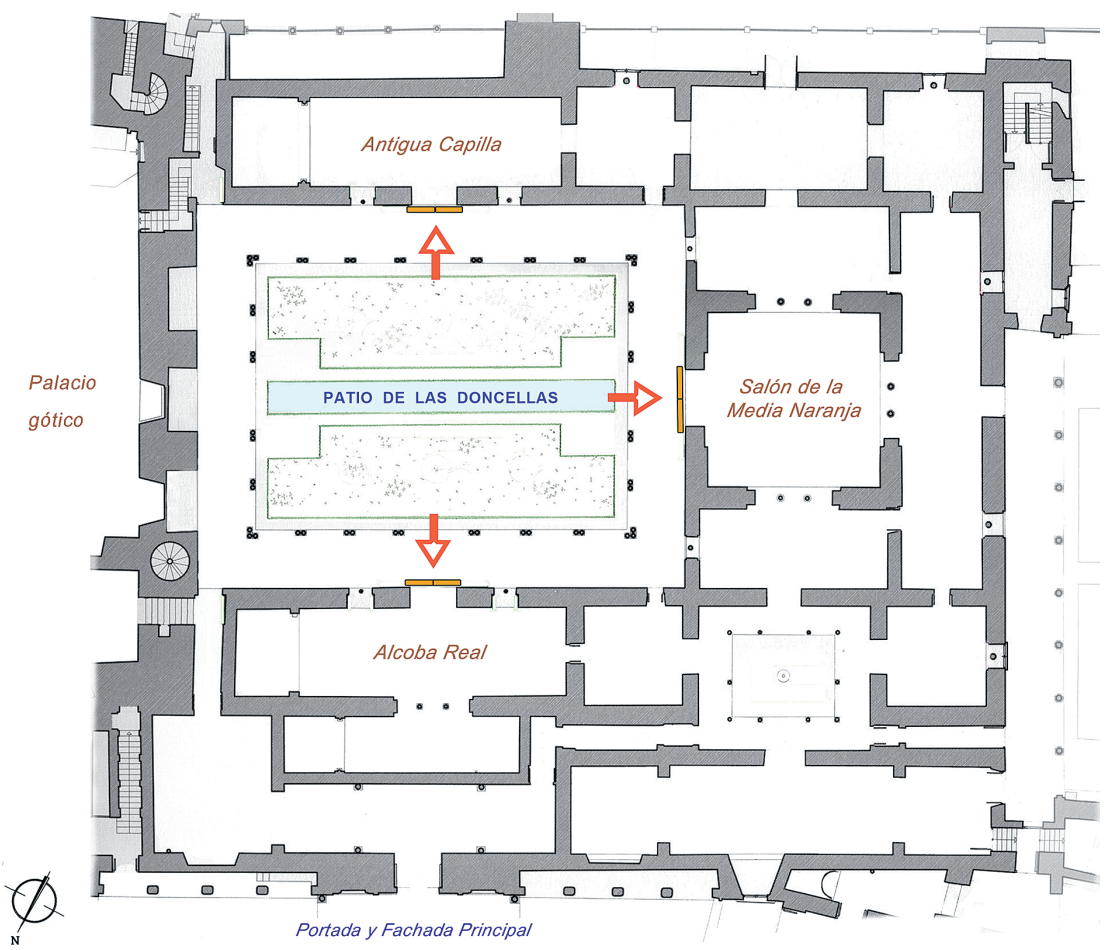

Fig. 1. Las tres grandes puertas de carpintería mudéjar con sus diferentes diseños, y su emplazamiento en torno al patio de las Doncellas del palacio de Pedro I (S.F.A.).

a un momento distinto en cuanto a su ejecución. Se trata de las puertas correspondientes al salón de la Media Naranja (hoy conocido como salón de Embajadores), salón del techo de Carlos V (antigua Capilla), y la Alcoba Real (vulgarmente conocida como dormitorio de los Reyes Moros). Entre estas puertas, la única fehacientemente datada es la del salón de la Media Naranja realizada

Arch. esp. arte, LXXXVIII, 352, OCTUBRE-DICIEMBRE 2015, 231-348 ISSN: 0004-0428, eISSN: 1988-8511, doi: 10.3989/aearte.2015.21 
en 1366, según figura epigrafiado en la talla de sus largueros, mientras las otras dos son evidentemente de momentos anteriores, y al parecer reutilizadas en la construcción del palacio en su etapa original con Pedro I.

Estas tres grandes puertas que abren hacia el patio principal, sólo tienen en común la técnica constructiva, ya que son apeinazadas y, por tanto, con la decoración de lacería que se repite en sus caras anterior y posterior. Pueden parecer muy semejantes al contemplarlas desde el centro del patio, situadas en el eje de las pandas Norte, Sur y Oeste. Sin embargo, al colocar sus dibujos sobre el papel en un mismo plano y usando la misma escala, empezamos a apreciar sus diferencias (fig. 1). Tras un minucioso análisis llevado a cabo con motivo de los trabajos de restauración, pudimos constatar que eran diferentes tanto en las estructuras como en la ornamentación, y así apreciamos diferencias en el sistema constructivo, en la composición geométrica y factura de sus decoraciones, en la paleta de colores usada según los vestigios analizados, etc. ${ }^{2}$.

A la vista de tales variaciones estilísticas y técnicas, y dado que la puerta del salón de la Media Naranja es la única fehacientemente datada (1366), podemos afirmar que tanto la puerta de la Antigua Capilla, como la de la Alcoba Real formaron parte de los materiales y piezas de valor que, procedentes de construcciones anteriores, fueron reutilizados en el momento de la construcción del palacio, aunque no podríamos datarlas con precisión.

Una vez confirmado que cada una de estas tres grandes puertas son de distinta cronología, se nos despierta la curiosidad por conocer el origen o ubicación de las que ya existían con anterioridad a la construcción del palacio de don Pedro, para lo que comenzamos con la observación de planos y cualquier documentación que nos pudiera ser útil a tal fin, obviamente buscando datos anteriores a dicha construcción. Tal es el caso del palacio gótico construido por Alfonso X el Sabio (12521284).

Este palacio gótico tuvo que construirse en los primeros años de su reinado, entre 1252 y 1260 , siendo Sevilla una de las ciudades más amadas por dicho rey, sede de la corte castellana durante largos años, y el principal foco para la cultura y el conocimiento de la época en el occidente europeo, con el fomento de las artes y las ciencias promovidas por el rey Sabio. El edificio ha sido ya estudiado en profundidad por distintos autores que han ido acumulando información sobre el mismo. A través de obras alfonsíes como las Cántigas de Santa María, las Partidas etc., podemos tener una referencia respecto de normas, materiales y técnicas constructivas de la época. En este sentido, disponemos de un trabajo de José Guerrero Lovillo "Estudio arqueológico de las miniaturas de las Cántigas de Santa María..." que es de gran interés ${ }^{3}$. Por otro lado, Rafael Cómez Ramos en su magnífico trabajo sobre arquitectura Alfonsí nos ofrece un minucioso y detallado estudio sobre la arquitectura de este palacio ${ }^{4}$. Por su parte Rafael Manzano Martos en su etapa de conservador de estos palacios realiza una serie de trabajos, sobre todo con la recuperación de algunas galerías en el patio de Crucero, que suponen el punto de partida para posteriores investigaciones, realizadas a partir de entonces por iniciativa del Patronato del Real Alcázar, como son las investigaciones arqueológicas del equipo de M. A. Tabales, o el levantamiento de planimetría del estado actual, además de las hipótesis sobre su origen, realizados por la Escuela de Estudios Árabes del CSIC bajo la dirección de Antonio Almagro.

De este modo podemos contar con una serie de representaciones gráficas que nos muestran como pudo ser el palacio gótico originalmente, construido a partir de un palacio almohade anterior, según cada uno de los distintos autores. En estas representaciones gráficas podemos apreciar el tránsito de una edificación almohade a otra cristiana que ocupa su mismo emplazamiento (fig. 2).

\footnotetext{
2 Fernández Aguilera, 2012: 117-128.

${ }^{3}$ Guerrero Lovillo, 1949.

${ }^{4}$ Cómez Ramos, 1974.
}

Arch. esp. arte, LXXXVIII, 352, oCTUBRE-DICIEMBRE 2015, 331-348 ISSN: 0004-0428, eISSN: 1988-8511, doi: 10.3989/aearte.2015.21 



Fig. 2. Transición de palacio almohade a gótico. Adaptación del autor, sobre dibujos publicados por M. A. Tabales en Apuntes del Alcázar de Sevilla, n. ${ }^{\circ}$ 6, 2005.

La primera observación en esta nueva construcción, en este caso de estilo gótico, es que sobrepasa la muralla existente, tanto hacia el Sur como hacia el Oeste. Quizás aplicando la nueva norma de no construir adosándose a las murallas, aunque en este caso se utilizan parte de ellas como cimentación. En segundo lugar observamos que la apertura de huecos hacia el exterior suponía un gran

Arch. esp. arte, LXXXVIII, 352, OCTUBRE-DICIEMBRE 2015, 231-348 ISSN: 0004-0428, eISSN: 1988-8511, doi: 10.3989/aearte.2015.21 


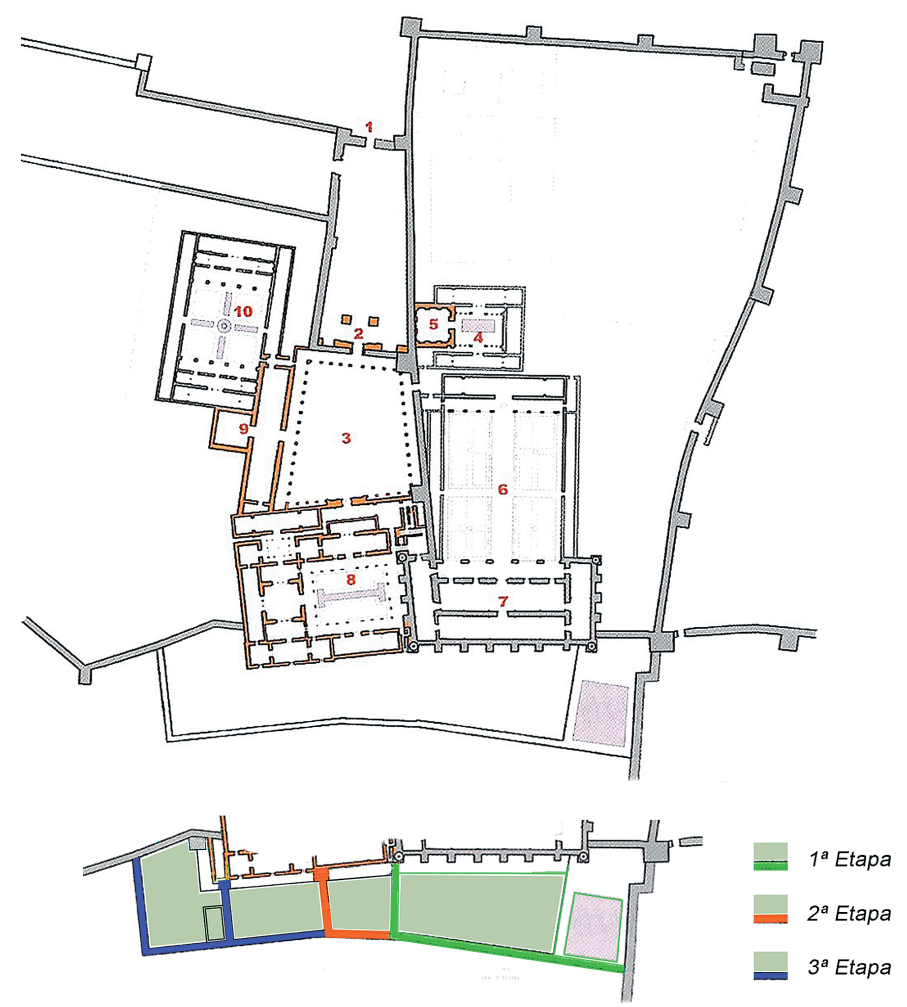

Fig. 3 Sup. Planta del Alcázar de Sevilla en tiempos de Pedro I según Antonio Almagro.

En la parte inferior, detalles de la progresión de las etapas constructivas de la cerca de los jardines (S.F.A.).

cambio respecto de "la tradición musulmana de hacer vida doméstica recogida, sin ninguna proyección al exterior"s.

Al dotar al edificio de nuevos vanos hacia fuera que proporcionan luz y ventilación, y no contar ya con la muralla externa, toda la construcción quedaba expuesta al exterior. Tengamos en cuenta que los terrenos inmediatos al palacio eran de uso agrícola, y se hacía necesario algún tipo de cerramiento con que proporcionarle la suficiente seguridad y protección de la intimidad. Este detalle, aunque conocido por los distintos autores, parece pasar desapercibido ya que no lo representan en sus dibujos. No obstante podemos considerar como excepción un patio que se genera al Oeste de esta construcción, como nos muestra en sus dibujos el equipo de arqueólogos tras la excavación realizada en el Patio de las Doncellas, donde aparecieron los restos de unos pilares de ladrillo de época cristiana y anteriores al palacio de don Pedro. En este caso se aprovecha la demolición de un edificio almohade en este recinto, que fue necesaria para la construcción del ala Oeste del palacio gótico, donde actualmente se encuentra la capilla de dicho palacio, y cuyas ventanas abrirían hacia ese patio.

En el plano que representa Almagro como planta del Alcázar en tiempos de Pedro I (fig. 3 sup.), se observa como queda delimitado el jardín al Sur de los palacios mediante un muro con ciertos quiebros en su trazado, que aún hoy se conserva, generando un espacio continuo y sin divisiones. Para nuestro propósito estos tramos transversales de muro, aquí omitidos, son ineludibles como testigos de su evolución, ya que también son originales, como podremos comprobar (fig. 3 inf.). Estas com-

\footnotetext{
${ }^{5}$ Guerrero Lovillo, 1949: 232.

${ }^{6}$ Almagro Gorbea, 2007: 168.
}

Arch. esp. arte, LXXXVIII, 352, oCTUBRE-DICIEMBRE 2015, 331-348 ISSN: 0004-0428, eISSN: 1988-8511, doi: 10.3989/aearte.2015.21 


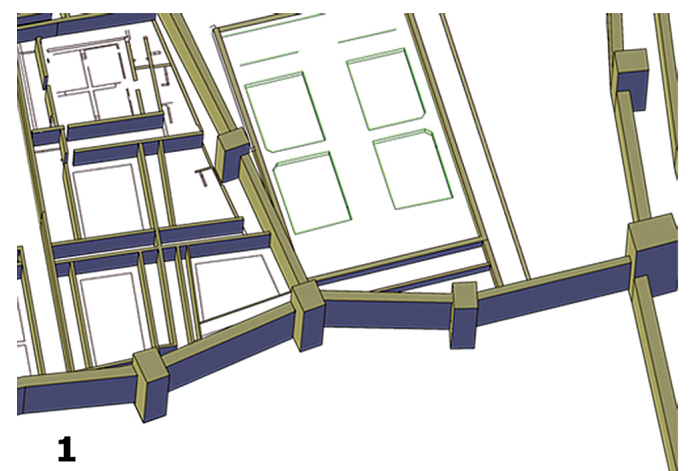

1
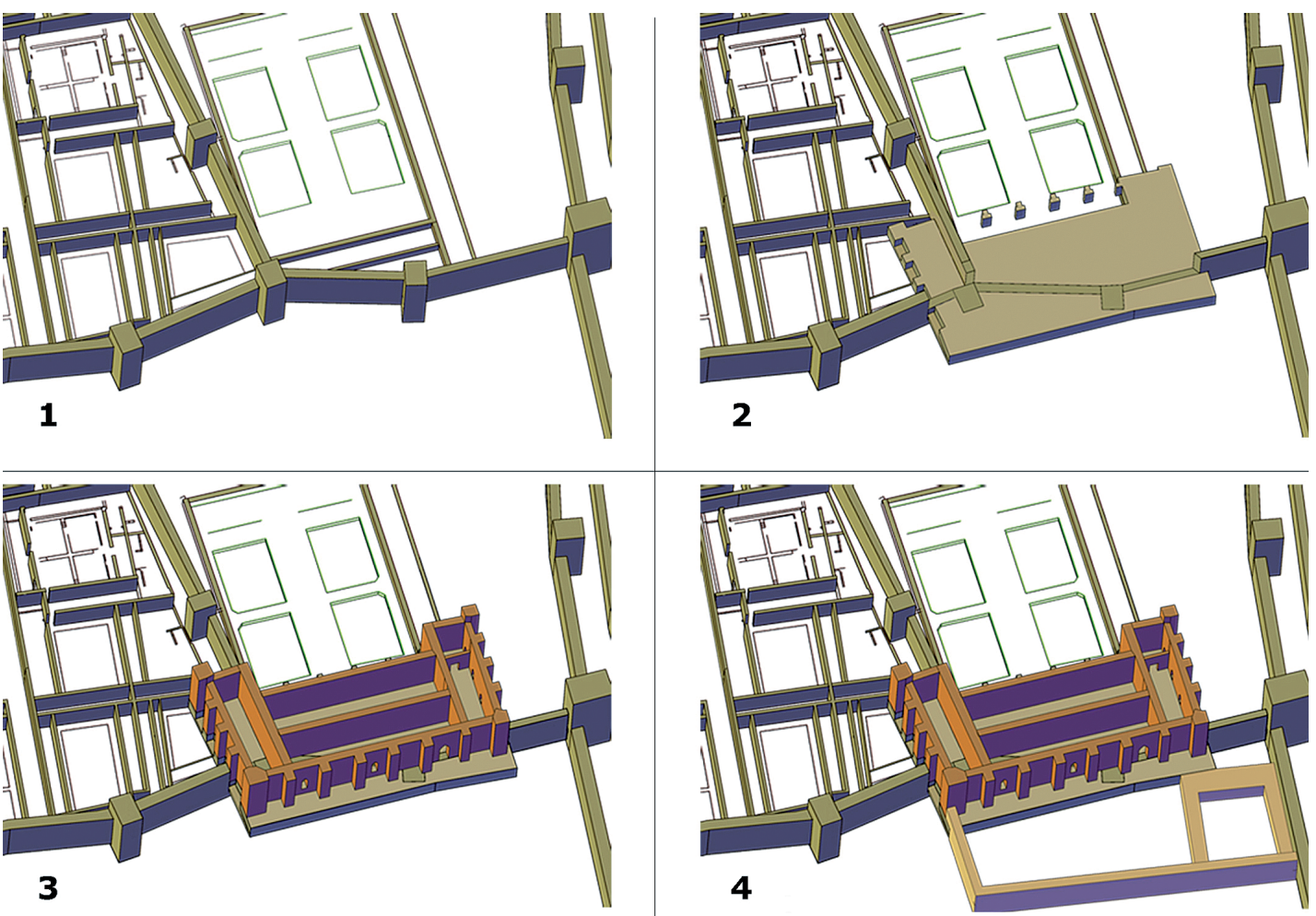

Fig. 4. Proceso constructivo del palacio gótico, trascendiendo la muralla almohade (S.F.A.).

partimentaciones en la zona de los jardines al Sur de los palacios, se corresponden con las distintas etapas del proceso evolutivo en la construcción de los mismos. Se trata de unos muros que aún hoy se conservan aunque con las modificaciones soportadas a lo largo del tiempo, entre las que las más señaladas fueron las obras de Vermondo Resta como maestro mayor del Alcázar entre 1603 y 1625.

Centrándonos en la construcción del palacio gótico, vemos como toda la obra mandada hacer por el rey Sabio, como arquitectura de identidad cristiana y diferenciándose de todo lo anterior, está realizada en piedra por los canteros llegados desde el Norte y conocedores de esta forma de construir. Este sería su proceso: En primer lugar, una vez replanteada la cimentación sobre piedra se crea una plataforma como base, utilizando de relleno incluso el material de derribo de la propia muralla (fig. 4-1 y 2). Sobre esta plataforma se eleva la construcción de las distintas naves (fig. 4-3). Y por último se delimitan los espacios exteriores con la construcción de la correspondiente cerca de protección (fig. 4-4).

Así debemos afirmar que en la construcción del palacio gótico, además de sobrepasar la antigua cerca almohade, se genera un nuevo espacio delimitado por una nueva cerca hacia el Sur con un tramo transversal que se apoya en el vértice Suroeste del mismo, al que también consideramos parte del palacio gótico. Actualmente este espacio es ocupado por el jardín de la Danza y el estanque de Mercurio.

Respecto de este estanque habría que hacer otra observación. En el trabajo de Rafael Cómez sobre arquitectura Alfonsí, nos ofrece referencias sobre distintos documentos, entre los que destacamos uno en los siguientes términos: "No son muchas las referencias al palacio gótico del monarca en Sevilla, sin embargo, se pueden hallar algunas como la del 22 de marzo de 1254 en que 
el Rey daba todos sus molinos al concejo de Sevilla a cambio de que llegase el agua de los Caños "a los nuestros palacios del alcaçar" /.../ "a las cocinas e a la huerta mayor"“"7.

Y en otra referencia del mismo autor: "Don Alfonso en el privilegio de 22 de marzo de 1254, mandaba "de fazer venir el agua de los Caños a los nuestros palacios del Alcázar de Sevilla e a la huerta deben ahofar ${ }^{8}$, tanta quanta ouier menester de las tapias adentro". Ello demuestra las necesidades de un gran palacio de múltiples dependencias..." “9

Nuestra opinión es que al construir la traída de aguas de los Caños hasta el Alcázar en aquellos años de mitad del siglo XIII, también se hubo de construir un gran estanque donde almacenarla y administrarla, en un espacio protegido y controlado como es este que se genera con la construcción del palacio gótico. Tengamos en cuenta que el citado conducto llega desde la Puerta de Carmona, utilizando la muralla, hasta la torre que cierra el recinto del Alcázar en el vértice Sureste, precisamente la más próxima al palacio gótico y donde se encuentra el citado estanque, que aunque ha sido modificado y transformado en distintas intervenciones a lo largo de su historia, ha llegado hasta nosotros con el nombre actual de estanque de Mercurio, o estanque del "Chorrón". De este modo podemos ver ya construido el palacio gótico, sobre el que más tarde se adosará el palacio mudéjar.

En la zona de contacto entre el palacio gótico y el mudéjar, se generan unos espacios singulares e interesantes para su estudio, resultando una incógnita para los investigadores, y a lo que esperamos dar una explicación en el presente trabajo. En el flanco Sur del palacio de don Pedro vemos como toda la construcción se eleva sobre un sótano abovedado que se construye sobrepasando la muralla con el fin de recuperar la cota de edificación, como se hiciera anteriormente con la construcción del palacio gótico.

Al observar este sótano sobre el terreno distinguimos dos tramos totalmente diferenciados tanto en proporciones como en el sistema constructivo, comprobando que se trata de dos sótanos distintos y no de una única construcción, como veremos. En primer lugar, el tramo más próximo al palacio gótico, sobre el que se construye la "Antigua Capilla" se subdivide en dos y se conforma en bóveda de arcos apuntados y anchura de 4,2 $\mathrm{m}$. El segundo tramo de sótano, que ocupa el resto de la crujía Sur del palacio, es de una nave continua en bóveda de plementería sobre arcos de medio punto y una anchura de 5,4 m. Del mismo modo comprobamos como en la construcción de las plantas superiores también se reflejan estas diferencias en el ancho de las correspondientes salas (fig. 5).

Tras estas observaciones nos planteamos la siguiente reflexión: Si la construcción del palacio mudéjar se hizo a partir de un proyecto unitario del arquitecto del rey don Pedro, el maestro Yusuf del Aljarafe, llama la atención que estas diferencias o cambios de criterio en el ala Sur desde los cimientos, o desde los comienzos de la obra, no se materializaran en un cambio completo del proyecto, que hubiera dado como resultado un ala uniforme y homogénea.

Del mismo modo y continuando con nuestras observaciones en este ámbito del palacio, nos ha llamado la atención la discontinuidad que se produce en el muro exterior de esta crujía Sur, vista desde los jardines. Con una aproximación a esta parte del paramento comprobamos como el muro que cierra las salas contiguas a la Antigua Capilla y el Mirador en toda su altura, se superpone sobre el anterior (fig. 6). En un examen más detallado pudimos comprobar además que en la labor de construcción están diferenciados y no existe trabazón entre ambos muros. Este solapamiento de un muro sobre otro evidencia el haber sido construidos en distintos momentos.

\footnotetext{
${ }^{7}$ Cómez Ramos, 1974: 49. Tomada de Arch. Municipal de Sevilla, carp. I. Núm 8.

${ }^{8}$ El profesor Ladero Quesada (M.A. Castillo (ed.), 2001: 28) lo transcribe como "la huerta de Ven Ahoar, que es la del Rey".

${ }^{9}$ Cómez Ramos, 1974: 151.
}

Arch. esp. arte, LXXXVIII, 352, oCTUBRE-DICIEMBRE 2015, 331-348

ISSN: 0004-0428, eISSN: 1988-8511, doi: 10.3989/aearte.2015.21 

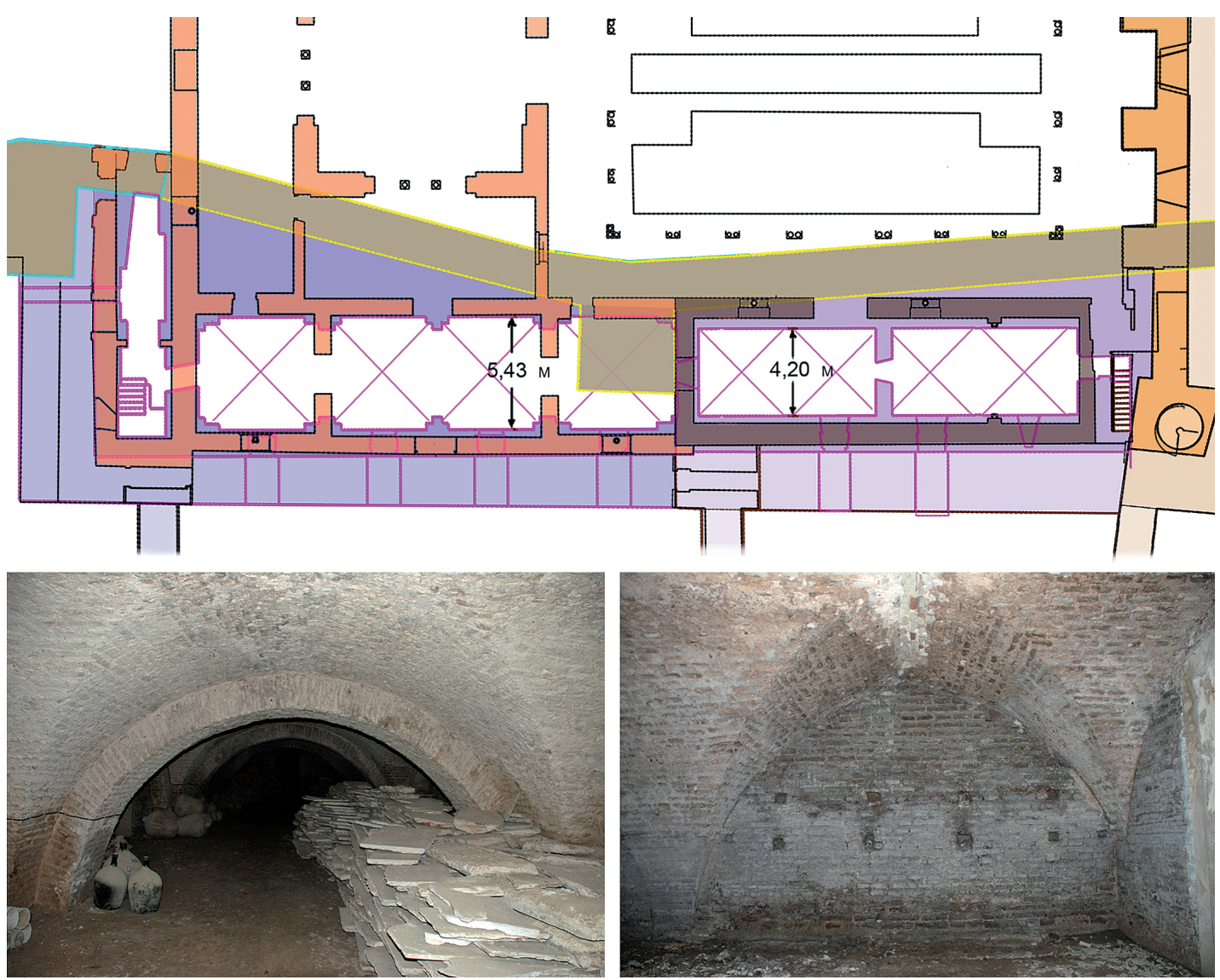

Fig. 5 Sup.: Planta del sótano en el ala Sur, trascendiendo la muralla almohade, sobre el que se construye la crujía Sur del palacio mudéjar Inf: Aspectos del interior de los sótanos del palacio mudéjar en sus dos tramos: dcha. arco apuntado; izqda. arcos de medio punto (S.F.A.).

En esta parte del palacio edificado sobre el primer tramo de sótano se encuentra la sala conocida como "sala del techo de Carlos V", también conocida como "Antigua Capilla", con su puerta de acceso desde el patio principal (patio de las Doncellas), siendo precisamente una de las puertas estudiadas como anteriores, y cuya posible ubicación previa comenzamos a buscar. Sobre esta estancia, además, se encuentran el "dormitorio de don Pedro" y el "Mirador", ambas en la planta superior.

Durante la restauración del artesonado en la sala del techo de Carlos V en el año 2009, hicimos un estudio detallado de los muros en su trasdós, en el que se sacaron a la luz las evidencias de que su anterior armadura es la que actualmente cubre el Mirador en la planta superior, y cuyo traslado se realizó con motivo de la construcción de este nuevo artesonado de estilo renacentista, entre los años 1540 y 1542, en época del emperador Carlos V, y dentro del plan de obras que en la etapa de los Austrias terminaron duplicando la distribución del palacio en la planta alta ${ }^{10}$.

\footnotetext{
${ }^{10}$ Pérez Ferrer y Fernández Aguilera, 2010: 38-61.
}

Arch. esp. arte, LXXXVIII, 352, OCTUBRE-DICIEMBRE 2015, 231-348 ISSN: 0004-0428, eISSN: 1988-8511, doi: 10.3989/aearte.2015.21 


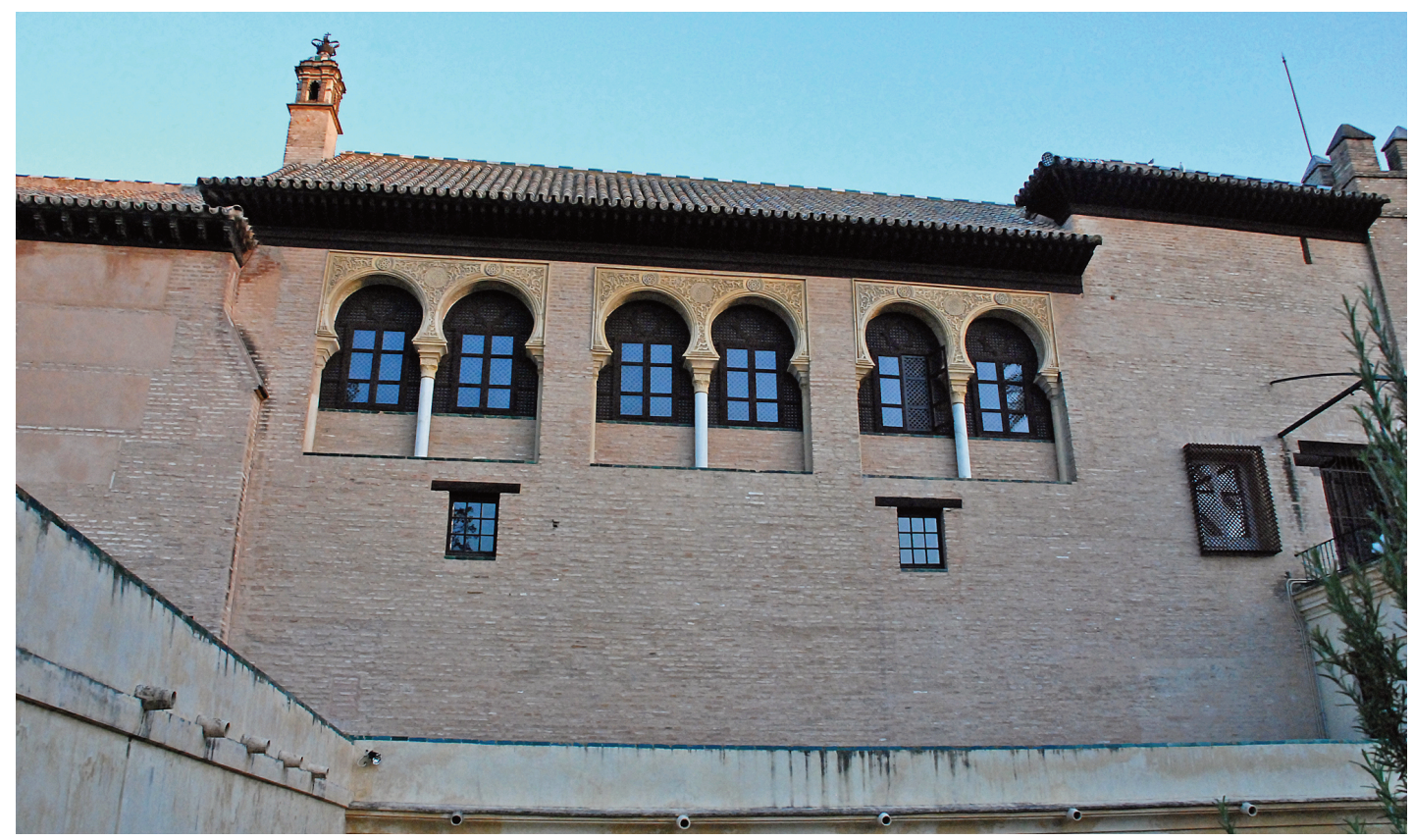

Fig. 6. Vista del mirador. A la izquierda, coincidiendo con el escalonamiento de la cubierta, el encuentro entre los dos paramentos (solapado) en el flanco Sur del palacio (S.F.A.).

Si nos centramos en esta pieza hoy conocida como "Mirador de los Reyes Católicos", llamarlo de esta forma es usar una nomenclatura que se le aplica más como dato identificativo que como dato cronológico, ya que para algunos autores es obra del rey don Pedro y para otros fue obra de estos monarcas. Se trata de un espacio en la planta alta, sobre el salón del techo de Carlos V, bien diferenciado del resto del palacio, y que ha sido objeto de controversias respecto de su origen, pues se le aplican distintas etapas constructivas y de reformas.

Hasta las actuaciones que Rafael Manzano realizara con el fin de solucionar los problemas de cubiertas que presentaba el palacio en el decenio de los años 70 del pasado siglo, este espacio en la crujía Sur junto al dormitorio de don Pedro, era conocido como la "Sala Alta" con la misma cota de suelo que el resto de la planta alta del palacio. Este nombre se le venía aplicando desde aquella transformación de 1542 en que se colocó la nueva techumbre plana en la estancia inferior (antigua Capilla), se cegaron sus vanos, y se convirtió en un espacio de singular altura.

Contaba con una puerta centrada en el paramento, como acceso desde la galería alta del Patio, galería que, además, estaba cubierta con un falso techo a una altura reducida. Frente a la puerta, dos balcones abrían hacia los jardines. Durante las tareas de saneamiento de los paramentos y levantamiento de los revestimientos defectuosos, se pudieron localizar ciertos huecos anteriores que habían quedado ocultos en el muro, y que en estas tareas se terminan recuperando. En esta intervención de Manzano se ponen al descubierto estos huecos, que resultaron geminados en arcos de herradura que habían sido tabicados en aquella transformación del siglo XVI, recuperándose su aspecto original en cuanto a cerramientos. Además, en el interior, aparecen vestigios en los muros que marcaban la cota original de suelo, a unos dos metros por encima de la cota de planta alta, con restos de material cerámico mudéjar en los bordes como testigos de lo que fue su pavimento con una ligera pendiente hacia el exterior del palacio. Con la colocación de un nuevo forjado a

Arch. esp. arte, LXXXVIII, 352, oCTUBRE-DICIEMBRE 2015, 331-348 ISSN: 0004-0428, eISSN: 1988-8511, doi: 10.3989/aearte.2015.21 


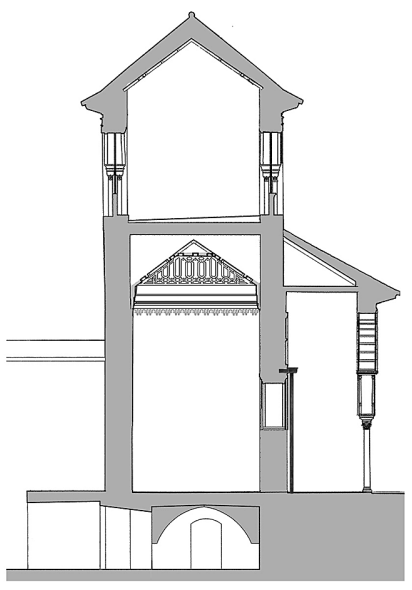

A Construcción original

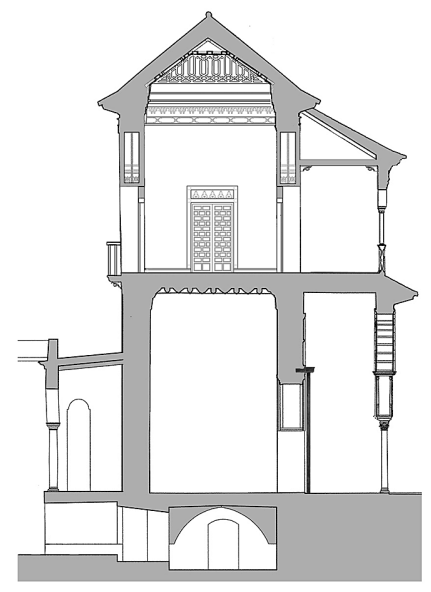

B Transformación de 1541

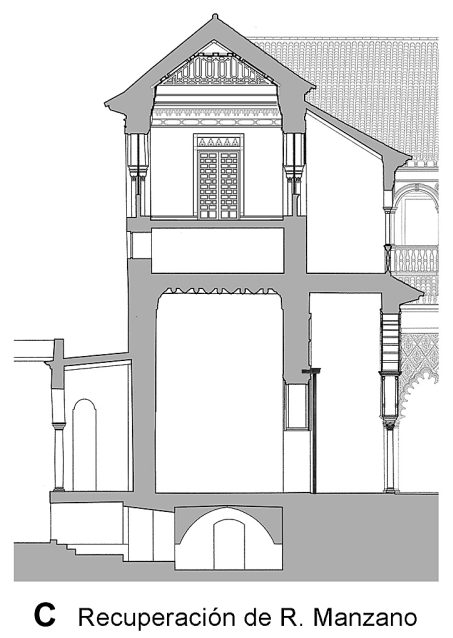

Fig. 7. Sección del ámbito del Mirador en sus tres configuraciones distintas (S.F.A.).

este nivel, Manzano procura recuperar aquella cota de suelo, generándose una entreplanta de escasa altura (175 cm, aproximadamente) (fig. 7).

Con el descubrimiento de aquellos vanos originales emerge, además de columnas y capiteles, gran parte de la decoración de yeserías en las albanegas de los arcos y la decoración pictórica de carácter geométrico en el plano exterior de los antepechos. Y es precisamente en la cara interior de estos pretiles donde figuran los emblemas de los Reyes Católicos alternándose el yugo y el haz de flechas sobre decoración de claraboyas góticas fingidas, siendo este el motivo por el que debió recibir el nombre de "Mirador de los Reyes Católicos" atribuyendo su construcción a estos monarcas (fig. 8).

No todas las pinturas que aparecieron en estos antepechos pudieron ser reubicadas en el momento de la intervención, y algunos de aquellos restos, tras su adecuado tratamiento, se conservan hoy expuestos en otras dependencias del Real Alcázar.

Respecto a las atribuciones, comprobamos que han sido muchos los autores que han aplicado a los Reyes Católicos su autoría en diversas obras dentro de este palacio, basándose precisamente en la aparición de sus emblemas sobre las mismas, y en este sentido consideramos necesario hacer ciertas observaciones que nos ayuden a entender el procedimiento seguido en las actuaciones de éstos y otros monarcas.

Si nos basamos en pruebas documentales, tenemos en primer lugar las capitulaciones de 1478 entre los Reyes Católicos y Fco. de la Madrid, del que hemos obtenido copia procedente del Archivo de Simancas. En aquel documento, comentado por primera vez por Alfredo Morales y Juan Miguel Serrera en Laboratorio de Arte, en 1999, se hace referencia a la necesidad de reparaciones urgentes en determinadas estancias del Alcázar, dado el estado de abandono a que se había llegado. Entre esas reparaciones en el segundo folio figuran las necesarias en el "Mirador" expresándolo en la siguiente forma: "Otrosy, en el mirador, que reparen los pretiles que están todos desolados e lo tornen a enmendar de su azulejo e aliçares, que consyga con lo otro, e adobar su

${ }^{11}$ Morales y Serrera, 1999: 69-77. Fernández Gómez, 2011: 69.

Arch. esp. arte, LXXXVIII, 352, OCTUBRE-DICIEMBRE 2015, 231-348 ISSN: 0004-0428, eISSN: 1988-8511, doi: 10.3989/aearte.2015.21 


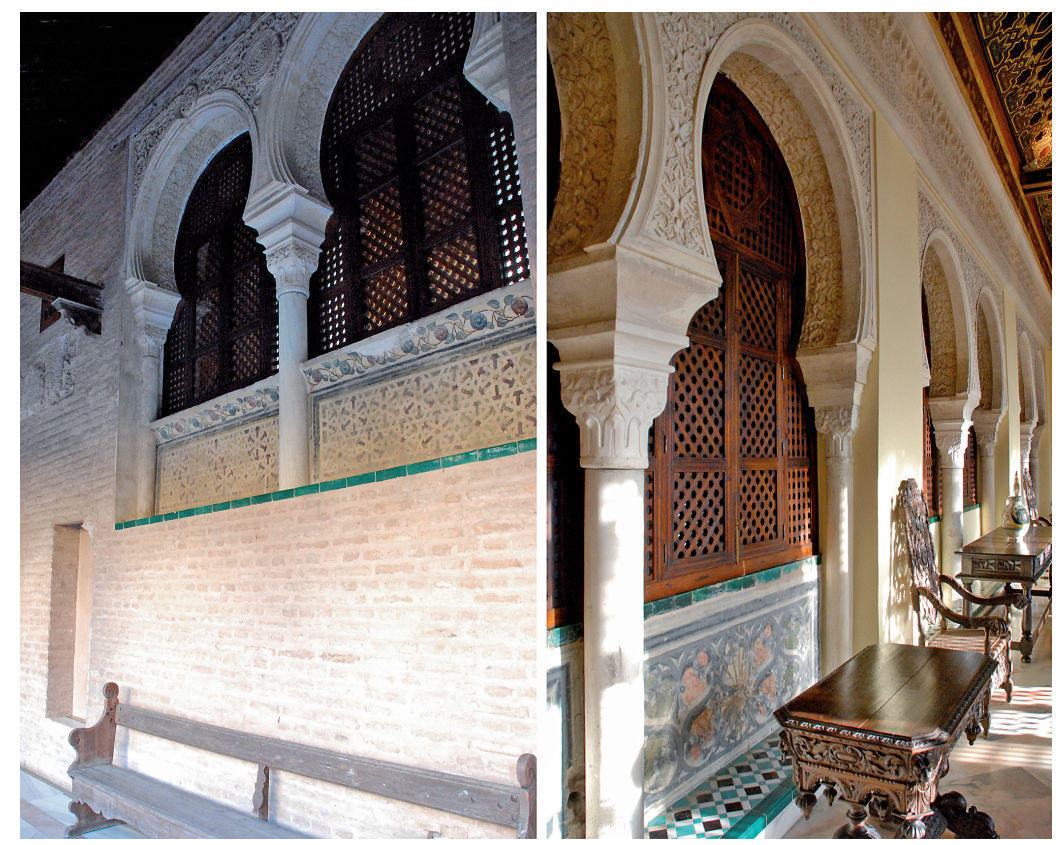

Fig. 8. Distintas vistas del mirador recuperado y la decoración pintada en sus pretiles. Izq.: exterior desde la galería alta con decoración geométrica. Dcha.: interior con emblemas de los Reyes Católicos. Obsérvense las diferencias de cota de suelo (S.F.A.).

gesería e reparar la entrada de la puerta de red"11 , llegando así a la conclusión de que existía con anterioridad a la redacción de este documento de 1478.

Por fortuna disponemos de otro documento, que ha podido adquirir el Patronato del Real Alcázar recientemente, en el que se recoge a modo de resumen el resultado de aquellas actuaciones, correspondientes a las capitulaciones que acabamos de ver, y que actualmente se encuentra expuesto en el Alcázar. Se trata del finiquito o resumen de ingresos y gastos en el periodo en que fue obrero Mayor, Francisco Ramírez de Madrid, con detalles de las obras realizadas en el Real Alcázar entre septiembre de 1478 y abril de 1495. En una lectura detenida del mismo vemos como en el folio 18 vto. se refleja este asiento de fecha 23 de enero de 1485 de un pago que se expresa en los siguientes términos: “... y en las claraboyas e azulejos e alizares e deuisas de armas que feziste fazer en el dicho Quarto Real e meter de pardillo entre las dichas claraboyas..."12. En este texto podemos subrayar que se paga por pintar y "meter de pardillo" unas divisas de armas, en este caso de los Reyes Católicos.

Atendiendo a este texto llegamos a la conclusión de que la colocación de sus emblemas o divisas por parte de los monarcas, era suficiente para marcar la autoridad y actualizar la propiedad sobre los distintos bienes de la corona. En el caso de los Reyes Católicos, podemos observar este proceder en muy diferentes localizaciones - la Aljafería o la Alhambra, por ejemplo- dentro de sus reinos. Aquí se ve la pertinencia de hacer estudios y análisis previos, y no basarnos sólo en la técnica del "post quem" o "ante quem", más apropiada para otro tipo de investigaciones arqueológicas, sobre todo en el subsuelo, antes de aplicar una atribución o autoría sólo con estos datos que nos puedan llevar a errores de cronología.

Continuando con nuestro Mirador, y haciendo un repaso sobre aquel estudio de las miniaturas de las Cántigas del rey Sabio que realizó tan cuidadosamente José Guerrero Lovillo, constatamos

\footnotetext{
${ }^{12}$ Fernández Gómez (ed.), 2011: 117.
} 


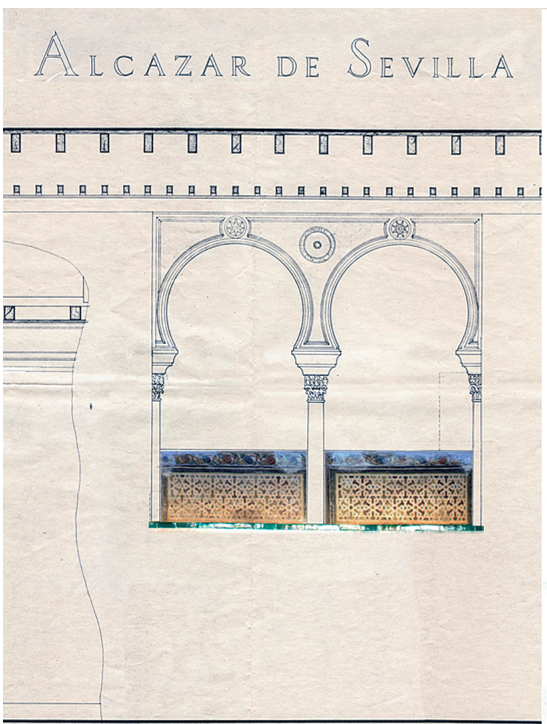

MIRADOR DE LOS REYES CATOLICOS
Guerrero Lovillo, pág. 236

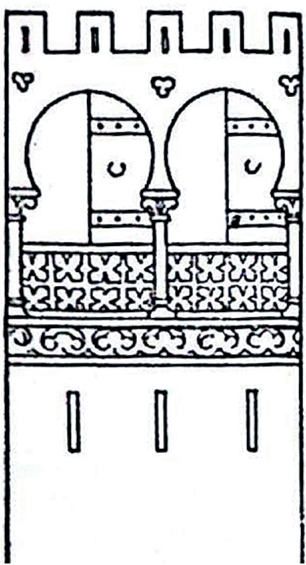

Fig. 244.-Mirador (lám. 159).

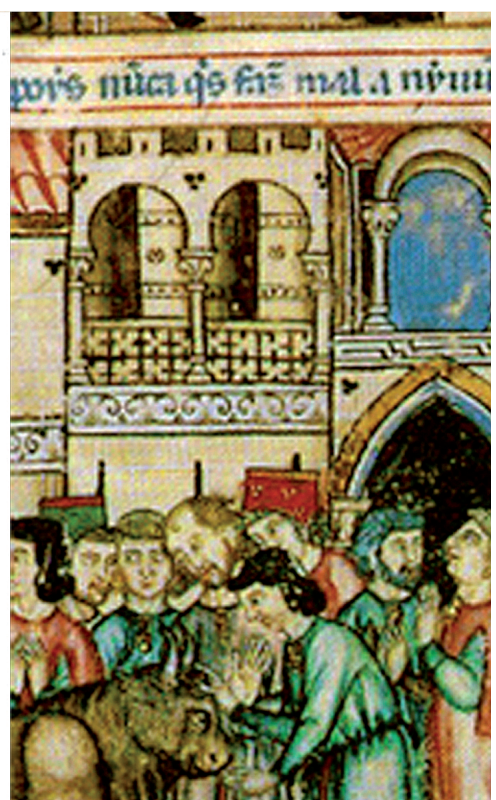

Fig. 9. Detalles de semejanzas entre el Mirador del Alcázar y el de la lámina de las Cántigas. Izq.: composición basada en un dibujo de Manzano. Centro: dibujo de Guerrero Lovillo. Dcha.: detalle de lámina de Cántiga 144 (S.F.A.).

la existencia de distintas tipologías de miradores. Tal es el caso de los que aparecen en las láminas de las Cántigas LXXIX o en la CXLIV, del que además este autor nos ofrece su propio dibujo. Al observar los detalles de esta miniatura nos resulta asombroso ver la cantidad de coincidencias que presenta con el diseño recuperado por Rafael Manzano en este Mirador (fig. 9), entre las que destacan:

- doble arco de herradura con alfiz y albanega decorada

- separación entre arcos con columna y capitel central, y apoyados sobre medias columnas y capiteles entregados a la jamba del hueco en ambos lados

- antepecho retranqueado respecto del muro, revestido con decoración geométrica al exterior, dejando exentos por delante los fustes de columnas, etcétera.

Con estas analogías disponemos de información más que suficiente para considerar la tipología de nuestro Mirador más apropiada de los siglos XIII y XIV, y por tanto anterior a los Reyes Católicos, aunque se pudieran colocar sus emblemas con posterioridad en sus paramentos interiores.

Abundando en estos detalles, si buscamos miradores entre los construidos en épocas más próximas a los Reyes Católicos, en Sevilla contamos, por ejemplo, con el de la casa de los Pinelo, construido entre 1516-20, actualmente sede de las Academias sevillanas, en el que tuvimos la oportunidad de intervenir en una restauración de 1993. En esta construcción los arcos son de medio punto, las columnas se apoyan sobre pilastras y el antepecho lo conforma una crestería calada, comprobándose que tanto los materiales como las técnicas constructivas son más próximos al Renacimiento, cosa que no ocurre con nuestro Mirador en el Alcázar.

Después de esta serie de consideraciones, veamos ahora el proceso constructivo en este ámbito del Mirador.

Arch. esp. arte, LXXXVIII, 352, OCTUBRE-DICIEMBRE 2015, 231-348 ISSN: 0004-0428, eISSN: 1988-8511, doi: 10.3989/aearte.2015.21 

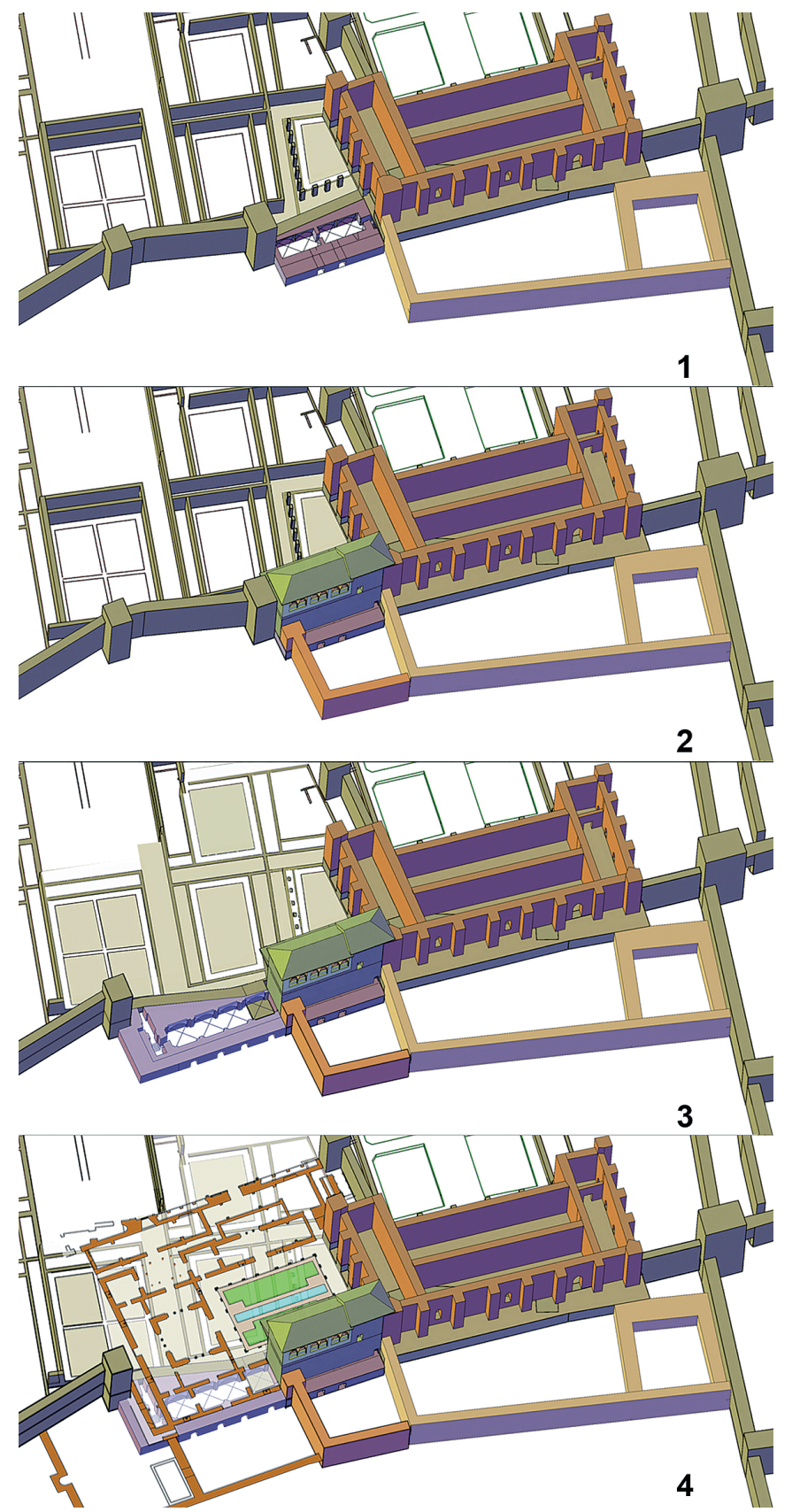

Fig. 10. El proceso constructivo del mirador y $1^{\mathrm{a}}$ etapa del palacio mudéjar (S.F.A.).

Tras la construcción del palacio gótico con su nuevo muro de cerramiento hacia el Sur, el resto de murallas y torreones de época almohade aún permanece en pie observándose que el tramo de lienzo de muralla, con 21,7 metros entre el palacio gótico y el torreón más próximo, coincide plenamente en su longitud con esta primera parte de la crujía Sur del palacio mudéjar, llegando a la conclusión de que se construyó apoyándose precisamente en ese torreón que aún permanecía, y por tanto con anterioridad al resto del palacio mudéjar del rey don Pedro, que vendría a solaparse posteriormente a esta construcción.

En este citado espacio entre el palacio gótico y el inmediato torreón almohade, se derriba el lienzo de muralla hasta la cota necesaria para uso como suelo y se construye, en perpendicular al muro más occidental del palacio gótico y trascendiendo la muralla, el primer tramo de sótano abovedado, con altura suficiente para alcanzar la citada cota. (fig. 10-1). Se trata de la construcción abovedada en ladrillo y con arcos apuntados antes mencionada.

Sobre este nuevo sótano se levanta la Antigua Capilla, y sobre ella el dormitorio de don Pedro y el Mirador. Hacia el Sur se crea una zona de protección con el levantamiento de una cerca en escuadra que al mismo tiempo le sirve de contrafuerte, como se hizo en la anterior construcción del palacio gótico, dando lugar, en esta ocasión, al conocido actualmente como jardín de Troya (fig. 10-2).

Atendiendo a estos detalles vemos la importancia de los tramos transversales de muro con que se cierran los jardines al Sur de los palacios, ya que nos muestran la evolución seguida en el proceso constructivo de los mismos, como hemos comentado anteriormente (fig. 3).

Arch. esp. arte, LXXXVIII, 352, oCTUBRE-DICIEMBRE 2015, 331-348 ISSN: 0004-0428, eISSN: 1988-8511, doi: 10.3989/aearte.2015.21 

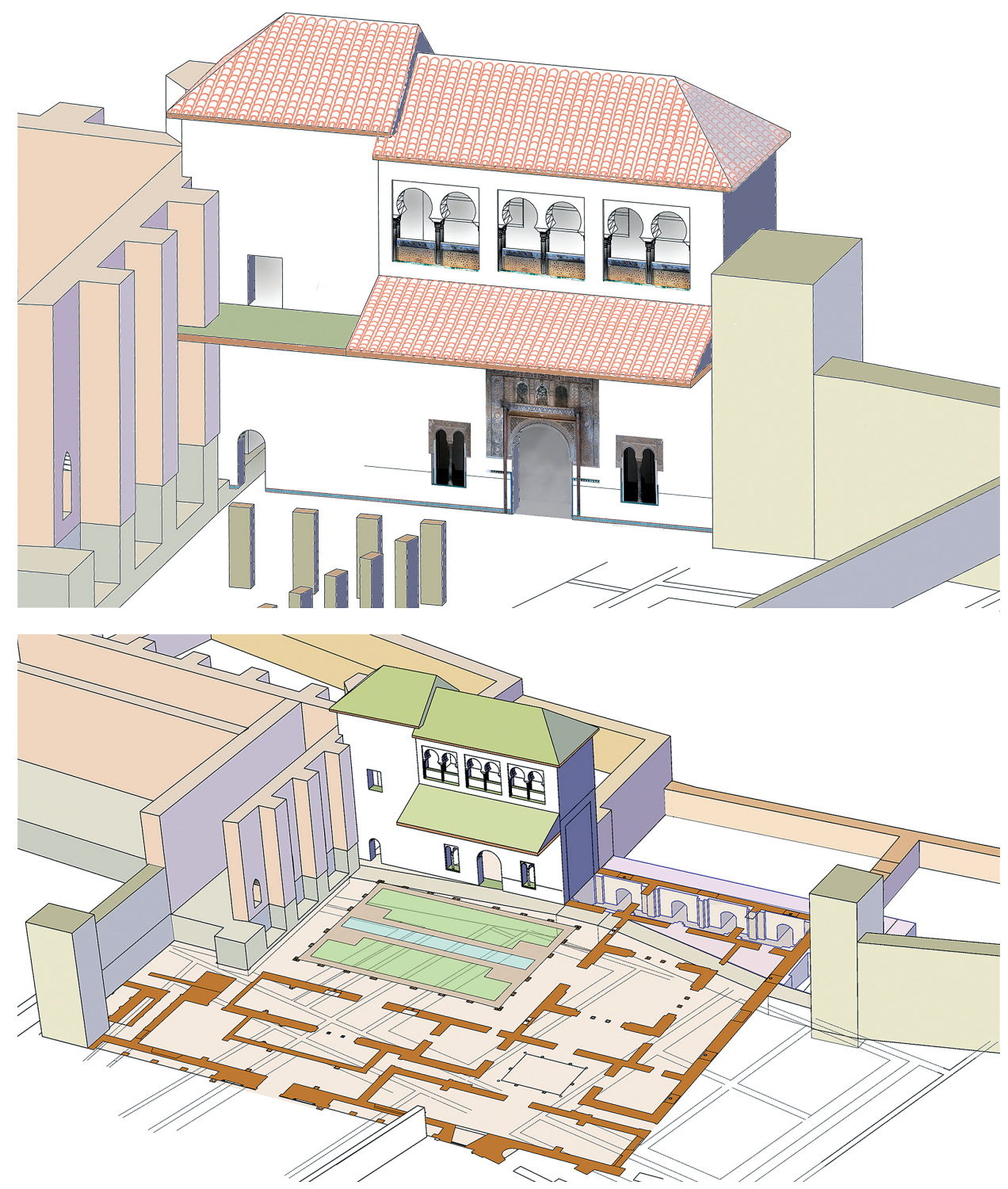

Fig. 11. Fase constructiva del Mirador, vista desde el Norte (interior del patio) y posterior proceso constructivo del palacio mudéjar (S.F.A.).

Viéndolo desde el Norte (fig. 11), el patio que ya se generó con la construcción del palacio gótico para dar luz a su nave más occidental, es ahora usado, además, como jardín interior que precede a esta construcción, contando muy posiblemente con una galería porticada en dos de sus lados, sobre los pilares ya documentados en la reciente excavación del Patio de las Doncellas. Pi-

13 Almagro Gorbea, 2005: 3. González Hernández, 2007:10.

Arch. esp. arte, LXXXVIII, 352, OCTUBRE-DICIEMBRE 2015, 231-348 ISSN: 0004-0428, eISSN: 1988-8511, doi: 10.3989/aearte.2015.21 
lares construidos en ladrillo, material tan mudéjar, y no en piedra como la totalidad del palacio gótico. Al fondo tendríamos, en planta alta y sobresaliendo por encima de la galería, el dormitorio de don Pedro y el Mirador. Desde esta posición serían visibles, hacia el Sur, no solo los jardines y la huerta, sino los campos de Tablada y el cauce del Guadalquivir hasta Coria del Río.

En planta baja, vista desde el patio, queda la sala con ventanas geminadas a ambos lados y una gran puerta central, tratándose precisamente de la puerta ya estudiada y datada como anterior a la construcción del palacio de don Pedro, para cuya búsqueda comenzamos esta investigación hace ya algunos años. En el encuentro con el muro del palacio gótico se abre un pasillo de tránsito al jardín posterior, que además sirve de acceso a las dependencias superiores a través de una estrecha escalera embutida y horadada en el citado muro, de la que aún hoy se conservan los últimos tramos.

Cuando el rey don Pedro decide la construcción de su palacio, su arquitecto lo hace apoyándose sobre esta construcción ya existente. Algo nada extraño, por otra parte, pues ya ocurrió en su palacio de Tordesillas donde, según los últimos estudios y con alguna controversia, conviven en su origen las construcciones del rey don Pedro, con las de su padre Alfonso $\mathrm{XI}^{13}$. Así se derriban la antigua torre almohade en que se apoyaba el Mirador y el lienzo de muralla hasta la siguiente torre, construyéndose el segundo tramo de sótano abovedado alineado con el anterior (fig. 10 -3). En este caso, el sótano se conforma también en ladrillo, pero sobre arcos de medio punto y mayor amplitud. Luego, hacia el interior, se prepara el solar para la construcción de todo el palacio mudéjar, demoliendo construcciones antiguas y usando la base de la muralla como muro de contención para los rellenos. De este modo queda conformada la nueva cota de edificación del palacio sobre el solar y el sótano. Hacia el Sur, se construye un nuevo cerramiento alineado sobre las anteriores tapias tras el Mirador y el palacio gótico, generándose nuevos espacios de protección, que han llegado hasta nosotros transformados en el "jardín de las Flores" y el "jardín de la Galera" (fig. $10-4$ ).

Con la construcción del nuevo palacio, el arquitecto del rey don Pedro se preocupa y consigue dar una imagen unitaria de su obra continuando la anterior (fig. 11 inf.), quedando de esta forma alineada toda la crujía Sur del palacio, con el pequeño escalón que provoca el solape de sus muros, visto desde los jardines.

Una vez confirmado que la construcción de este Mirador es posterior a la del palacio gótico, pero anterior a la del resto del palacio mudéjar, solo nos queda precisar su cronología dentro de esta banda en el tiempo que va desde el final del reinado de Alfonso X (1284), al comienzo del reinado de Pedro I (1350), es decir 66 años.

En ese periodo, la corona de Castilla estuvo en manos de tres monarcas: Sancho IV (12841295), Fernando IV (1295-1312) y Alfonso XI (1312-1350). A los dos primeros, hijo y nieto respectivamente de Alfonso X, no se les conoce actividad constructiva señalada, además de tener un reinado breve y belicoso, al contrario de lo que ocurre con Alfonso XI, quien además de haber tenido un periodo más prolongado de su reinado (38 años), aún excluyendo su etapa de minoría de edad y regencia de su abuela D. ${ }^{a}$ María de Molina, tuvo sobradas ocasiones para la actividad constructiva, como queda probado en las actuaciones llevadas a cabo en Tordesillas, ya citado anteriormente, o incluso en este mismo Alcázar de Sevilla con la construcción de la Sala de la Justicia junto al patio del Yeso.

Por otra parte, si consideramos que en este periodo se produce un fenómeno de transición entre el estilo gótico y el mudéjar, no hay duda que esta obra queda ya lejos de la austeridad de aquel estilo que había llegado desde el Norte tras la conquista cristiana.

Pero en esta acotación temporal, viene a auxiliarnos una evidencia material de orden decorativo sobre la portada de yeserías donde se encuentra la puerta motivo de nuestra búsqueda. Se trata de la aparición de motivos heráldicos, en este caso tallados en el yeso, no sobrepuestos, y formando parte inseparable de la composición en medallones, que no es el caso de haber sido pintados como lo eran los emblemas de los Reyes Católicos que hemos visto anteriormente. En esta portada figuran alternándose las armas de Castilla, León y, lo más importante, la Orden de la Banda, mien-

Arch. esp. arte, LXXXVIII, 352, oCTUBRE-DICIEMBRE 2015, 331-348 ISSN: 0004-0428, eISSN: 1988-8511, doi: 10.3989/aearte.2015.21 

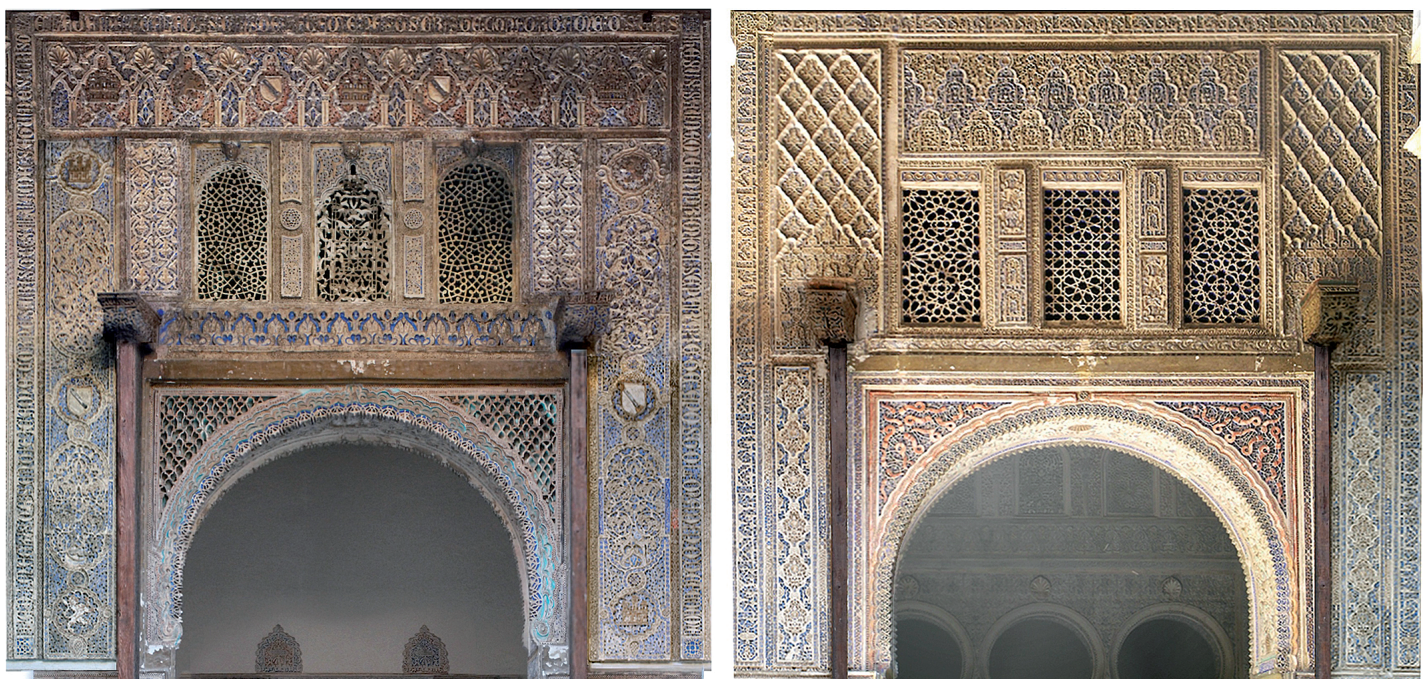

Fig. 12. Distintas decoraciones de yesería sobre las portadas. Izqda. Antigua Capilla; dcha. Alcoba Real (infografía del autor).

tras que en las yeserías de las demás portadas no aparecen motivos heráldicos, sino sólo motivos geométricos de sebka y ataurique, con profusión de epígrafes tallados en estilo cúfico.

Precisamente la presencia de esta talla, con la Orden de la Banda, nos afina la cronología para la construcción de esta portada en la etapa de reinado de Alfonso XI, ya que como sabemos fue el fundador de esta institución en 1332.

Pero aún hay más. Abundando en estas diferencias decorativas observamos que, aunque la decoración de yeserías que circundan los muros de las galerías del Patio de las Doncellas presentan uniformidad en su friso superior, no es así en la que enmarca estas tres portadas, pues la de la Antigua Capilla es claramente distinta a las otras dos (Alcoba Real y Madia Naranja), que a su vez comparten un mismo patrón decorativo. Y al hacer un estudio comparado de las yeserías que decoran esta portada con las otras dos, vemos las siguientes diferencias:

- en el primer caso, el vano de la puerta se enmarca con una franja decorada a modo de dintel, en cuyos extremos se ubican las quicialeras, mientras las demás puertas no cuentan con esa franja decorada y tienen sus quicialeras en espacios abiertos interrumpiendo la decoración. Del mismo modo, las albanegas de esta portada de yeso presentan una minuciosa decoración de minisebka de pared delgada y profundo calado, que le proporciona un singular aspecto que no vemos repetido en las otras dos puertas, donde sus albanegas están rellenas de formaciones vegetales de hojas, pimientos y tallos espirilíneos sobre un fondo plano. Y es más, este tipo de sebka calada no aparece en ninguna otra parte del palacio (fig. 12)

- en cuanto a las celosías que presentan los triples huecos de ventilación sobre cada puerta, en todos los casos que se pueden contemplar en las distintas dependencias y comunicaciones del edificio, son de formaciones geométricas poligonales y ruedas de lazo, tanto en interiores como en exteriores. Sin embargo, sobre la puerta de la Antigua Capilla podemos admirar una singular tipología de celosía elaborada en yeso, a base de formaciones geométricas lineales y curvilíneas, que tampoco se repite en ningún otro ámbito del palacio. 
Se trata por tanto, de una serie de diferencias con las que se pone de manifiesto que, aunque estén dentro del mismo estilo decorativo, estas yeserías pertenecen a distintos momentos de ejecución.

\section{Conclusiones}

A modo de resumen podríamos decir que tras los datos aportados por los trabajos de restauración que se vienen realizando en distintas etapas desde 1997, comenzamos la búsqueda del posible emplazamiento de una puerta, sabiendo que es anterior a la construcción del palacio de don Pedro, y para lo que hemos utilizado el siguiente itinerario:

1. La utilización de los datos aportados por las investigaciones arqueológicas recientes nos permiten ver la distribución de murallas y construcciones precedentes, que nos facilitan su comprensión espacial aunque sea de modo virtual.

2. Con una detallada observación del entorno hemos subrayado las evidencias de tipo constructivo, comprobando la existencia de sótanos diferenciados, el solapado de los muros visible desde el exterior, y la disposición de los muros de cerramiento de los jardines como testigos de la evolución constructiva de estos palacios. Toda una serie de evidencias que hasta ahora no habían sido consideradas ni apreciadas en los distintos y numerosos estudios realizados sobre estos edificios.

3. Con una lectura detenida de documentos de archivo de época de los Reyes Católicos, hemos podido afirmar que esta construcción con el Mirador es anterior también a estos monarcas, a pesar de la aparición de sus divisas sobre los paramentos, y que fueron motivo para su atribución.

4. Con razonamientos de tipo histórico podemos acotar su construcción dentro del reinado de Alfonso XI y con posterioridad a constituirse la orden de la Banda, es decir, entre 1332 y 1350.

5. A través de un minucioso análisis de los elementos decorativos que presenta la portada de esta construcción y comparándola con las demás del palacio mudéjar, se evidencian las diferencias por las que se confirma que corresponden a distintos proyectos.

Ya podemos afirmar que esta unidad arquitectónica que cubre los 21,7 m entre el palacio gótico y la inmediata torre almohade, desde el sótano hasta la cubierta del Mirador, es anterior a la obra del rey don Pedro y, por consiguiente, también lo es la portada con su decoración de yeserías y la puerta que cierra su sala en planta baja. Del mismo modo que lo son la armadura que cubre actualmente el Mirador, que antes lo estuvo en planta baja, la techumbre de la alhanía en el interior de la Antigua Capilla, e incluso la armadura que cubre la sala conocida como dormitorio de don Pedro en la planta alta, junto al Mirador.

Aquella puerta estudiada con motivo de su restauración entre 2001 y 2004, de la que concluíamos era anterior a la obra de don Pedro y cuya ubicación comenzamos buscando, no podemos considerarla como material de acarreo, ya que su emplazamiento original fue el que siempre ha tenido, y hoy la vemos totalmente integrada en el gran patio desde donde se articula todo el palacio mudéjar del rey don Pedro.

Arch. esp. arte, LXXXVIII, 352, oCTUBRE-DICIEMBRE 2015, 331-348 


\section{BIBLIOGRAFÍA}

Almagro Gorbea, A. (2005): "El Palacio de Pedro I en Tordesillas: realidad e hipótesis". En: Reales Sitios, n. 163. Madrid: Patrimonio Nacional, pp. 3-13.

Almagro Gorbea, A. (2007): “Los Reales Alcázares de Sevilla”. En: Arte Andalusí. Artigrama, n. 22. Zaragoza: Universidad de Zaragoza, pp. 155-185.

Castillo Oreja, M. A. (ed.) (2001): Los Alcázares Reales. Vigencia de los modelos tradicionales en la arquitectura áulica cristiana. Encuentros sobre Patrimonio. Madrid: Fundación BBVA (Col. Debates sobre Arte).

Cómez Ramos, R. (1974): Arquitectura Alfonsí. Sevilla: Diputación Prov. de Sevilla.

Cómez Ramos, R. (1996): El Alcázar del rey Don Pedro. Sevilla: Diputación Prov. de Sevilla.

Fernández Aguilera, Sebastián (2012): Portaventaneros mudéjares en el Real Alcázar de Sevilla. Sevilla: Archivo Hispalense (Col. Arte.) Diputación Prov. de Sevilla.

Fernández Gómez, Marcos (ed.) (2011): El Alcázar y las Atarazanas de Sevilla en el reinado de los Reyes Católicos. Las cuentas del obrero mayor Francisco de Madrid. Sevilla: Patronato del Real Alcázar y Casa Consistorial.

González Hernández, Ángel (2007): “De nuevo sobre el palacio del Rey Don Pedro I en Tordesillas”. En: Reales Sitios, n. 171. Madrid: Patrimonio Nacional, pp. 4-21.

Guerrero Lovillo, José (1949): Las Cántigas: estudio arqueológico de sus miniaturas. Madrid: Instituto Diego Velázquez-CSIC.

Marín Fidalgo, Ana (1990): El Alcázar de Sevilla bajo los Austrias (2 tomos). Sevilla: Ed. Guadalquivir.

Morales, Alfredo J. / Serrera, J. Miguel (1999): “Obras en los Reales Alcázares de Sevilla, en tiempos de los Reyes Católicos”. En: Laboratorio de Arte, n. 12. Sevilla: Universidad de Sevilla.

Pérez Ferrer, J.C. / Fernández Aguilera, S. (2010): "La Restauración del artesonado de la sala del techo de Carlos V”. En: Apuntes del Alcázar de Sevilla, n. 11. Sevilla: Patronato del Real Alcázar y Casa Consistorial, pp. 38-61.

Tabales Rodríguez, M. A. (2005): "El Patio de las Doncellas del palacio de Pedro I de Castilla. Génesis y transformación”. En: Apuntes del Alcázar de Sevilla, n. 6. Sevilla: Patronato del Real Alcázar y Casa Consistorial, pp. 6-43.

Fecha de recepción: 07-III-2014

Fecha de aceptación: 17-VI-2014

Arch. esp. arte, LXXXVIII, 352, OCTUBRE-DICIEMBRE 2015, 231-348 ISSN: 0004-0428, eISSN: 1988-8511, doi: 10.3989/aearte.2015.21 